Review

\title{
Organization of Twisting Lamellar Crystals in Birefringent Banded Polymer Spherulites: A Mini-Review
}

\author{
Jun Xu* (D), Haimu Ye (D), Shujing Zhang and Baohua Guo \\ Advanced Materials Laboratory of Ministry of Education, Department of Chemical Engineering, \\ Tsinghua University, Beijing 100084, China; yehaimu@cup.edu.cn (H.Y.); zhangsjcrystal@163.com (S.Z.); \\ bhguo@tsinghua.edu.cn (B.G.) \\ * Correspondence: jun-xu@tsinghua.edu.cn; Tel.: +86-10-6278-4740; Fax: +86-10-6278-4550
}

Received: 12 July 2017; Accepted: 2 August 2017; Published: 4 August 2017

\begin{abstract}
In this mini-review, we summarize the evidences of lamellar twisting in the birefringent banded polymer spherulites demonstrated by various characterization techniques, such as polarized optical microscopy, real-time atomic force microscopy, micro-focus wide angle X-ray diffraction, etc. The real-time observation of lamellar growth under atomic force microscopy unveiled the fine details of lamellar twisting and branching in the banded spherulites of poly( $R$-3-hydroxybutyrate-co-17 $\mathrm{mol} \%$ $R$-3-hydroxyhexanoate). Organization of the twisting lamellar crystals in the banded spherulites was revealed as well. The lamellar crystals change the orientation via twisting rather than the macro screw dislocations. In fact, macro screw dislocation provides the mechanism of synchronous twisting of neighboring lamellar crystals. The driving force of lamellar twisting is attributed to the anisotropic and unbalanced surface stresses. Besides molecular chirality, variation of the growth axis and the chemical groups on lamellar surface can change the distribution of the surface stresses, and thus may invert the handedness of lamellar twisting. Thus, based on both experimental results and physical reasoning, the relation between crystal chirality and chemical molecular structures has been suggested, via the bridge of the distribution of surface stresses. The factors affecting band spacing are briefly discussed. Some remaining questions and the perspective of the topic are highlighted.
\end{abstract}

Keywords: banded polymer spherulite; ringed spherulite; lamellar twisting; organization of lamellar crystals; surface stresses; chirality

When crystallized from quiescent melt or concentrated solution, polymer chains usually form spherulites consisted of multiple lamellar crystals radiating from the spherulite center. Observed under polarized optical microscope (POM), a spherulite shows the characteristic Maltese-cross extinction. Besides the Maltese cross, some spherulites demonstrate alternative bright and dark bands under POM. These spherulites are termed as banded spherulites or ringed spherulites. The band structure with different light intensities may result from different thicknesses or different birefringences but similar thickness. In the former case, the bands are due to the periodical modulation of sample thickness and there is no variation of refractive index in the spherulite. These nonbirefringent banded spherulites have been observed in some polymer single crystals formed from thin melt films [1] or solutions [2] and are reviewed by Li et al. [3] in this special issue. In the latter case, the birefringent bands can result from the wavy bending growth or twisting growth of crystals. The wavy bands have been reported in sheared liquid crystals [4,5], which do not form spherulites under the condition. In this mini-review, we focus on the birefringent banded spherulites, which consist of synchronously twisted lamellar crystals. The organization of the twisted lamellar crystals in the banded spherulites and the driving force for lamellar twisting will be briefly reviewed. The readers interested in this topic can also refer to the previous reviews for reference [6-9]. The main aim of this mini-review is to emphasize the 
evidences of lamellar twisting in the birefringent polymer banded spherulites from the combination of various characterization techniques and to reveal the organization of twisted lamellar crystals in the banded spherulites. Furthermore, the driving force of lamellar twisting will be briefly discussed. Among the several proposed mechanisms, the anisotropic and unbalanced surface stresses is the most probable mechanical origin of polymer lamellar twisting. Finally, the perspective of banded spherulites as a probe of the crystal nucleation mechanism and a platform of functional materials is expected.

\section{Evidence of Lamellar Twisting in Banded Polymer Spherulites}

\subsection{Observation of Banded Spherulites via Polarized Optical Microscopy}

Polarized optical microscopy (POM) is a simple method to distinguish the change of growth direction of crystals in the film plane and to check whether there exists twisting of crystals. Figure 1 presents some possible types of organization of lamellar crystals in the thin film and the corresponding polarized optical micrograph. If the crystals do not twist and only change their growth direction from the radial to tangential direction in the substrate plane (Figure 1a), there will be no bands in the bright field without polarizer and analyzer, namely, no difference of light intensity in the spherulite should be observed. Figure $1 \mathrm{~b}$ shows wavy bending of lamellae out of the film plane, which is termed as trans-rotational crystals and has been observed in spherulites of Se, its alloys, and other inorganic substances [10]. If the banded spherulites are consisted of wavy bending lamellar crystals (Figure 1a,b), there should be no shift of bands when tilting the sample stage under POM. In contrast, there will be shift of bands in the banded spherulites consisted of twisting lamellar crystals (Figure 1c,d). Spherulites consisting of helicoidally twisted lamellar crystals will demonstrate single or double bands under POM (Figure 1c), corresponding to uniaxial and biaxial birefringent crystal, respectively [11-14]. In contrast, banded spherulites composed of helically twisted lamellae will reveal zigzag extinction patterns under POM (Figure 1d). Figure 2a presents the single-banded spherulites of poly(L-lactide) (PLLA). Figure 2b shows the double birefringent bands in a poly(R-3-hydroxybutyrate) (PHB) spherulite, which consists of alternative bright-dark-gray-dark band patterns observed under the crossed polarizers. The double bands could only be attributed to twisting of crystals rather than simple change of growth directions in the film plane. Whether there is lamellar twisting can be checked via tilting the sample stage under POM, which provides a direct method to determine the handedness of lamellar twisting. When the banded spherulites are tilted around a radial direction, the bands will shift up or downwards, depending on the tilting direction and the twisting handedness (Figure 3) [15]. If the lamellar crystals twist steadily in the spherulite, the bands will move continuously with increasing tilt angle. If there is no lamellar twisting, the bands may not move while tilting the sample stage.

In the normal POM image, the light intensity is a coupling result of the birefringent retardation and the orientation of optical axes of the crystals. Some advanced optical microscopes, such as Polscope $[16,17]$ and Mueller matrix microscope $[18,19]$, can separate the birefringent retardation and the orientation of the slow optical axis. Polscope results of a poly(R-3-hydroxyvalerate) (PHV) banded spherulite containing an eye-like region are revealed in Figure 4 [17]. Figure 4a gives the birefringence retardation at each pixel and Figure $4 \mathrm{~b}$ draws the orientation of the slow optical axis (corresponding to the largest refractive index in the film plane) in the spherulite. The eye-like region shows smaller retardation, though the thicknesses of the two regions are the same. In the eye-like region, the slow optical axis is alternatively along the radial and circumferential direction. In the other region, the slow optical axis is always along the radial direction. Consequently, Polscope and Mueller matrix microscope would be powerful tools to distinguish different types of banded structures. 


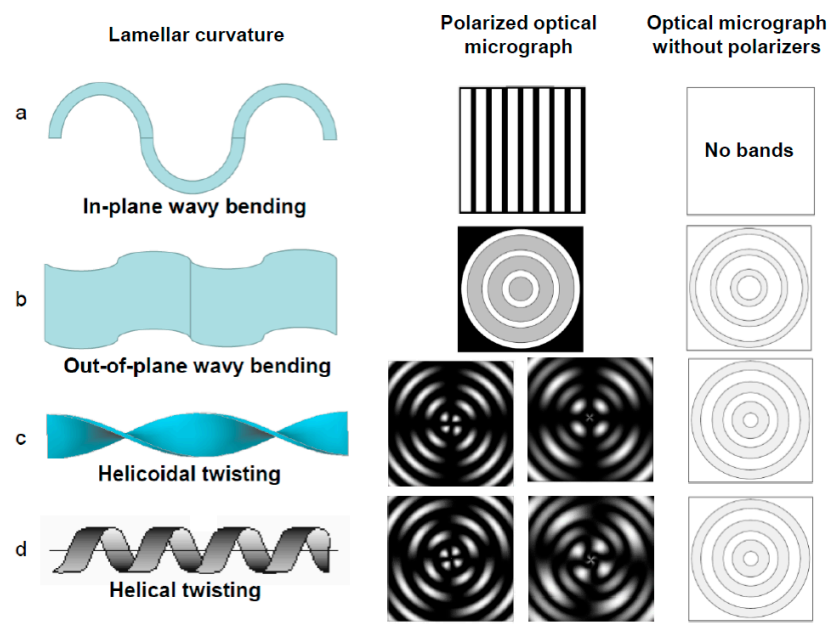

Figure 1. Organization scheme of curved lamellar crystals in thin film and the corresponding polarized optical micrographs: (a) In-plane wavy bending; (b) Out-of-plane wavy bending; (c) Helicoidal twisting; (d) Helical twisting of lamellar crystals and the corresponding pattern of optical micrograph. In (c,d), the second and third column corresponds to the simulated polarized optical micrograph of uniaxial and biaxial birefringent crystal, respectively. The simulated optical micrographs in the middle column of $(\mathbf{c}, \mathbf{d})$ are adapted from Ref. [14].
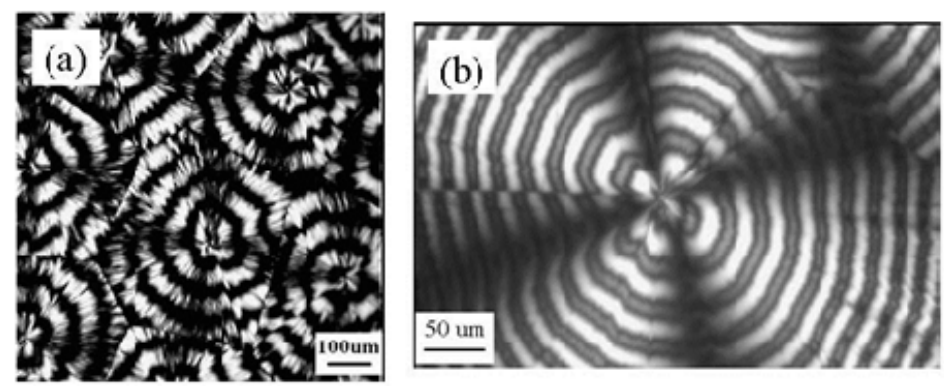

Figure 2. Two types of birefringent banded spherulites observed under polarized optical microscope: (a) Single banded spherulites of PLLA; (b) double banded spherulite of PHB.

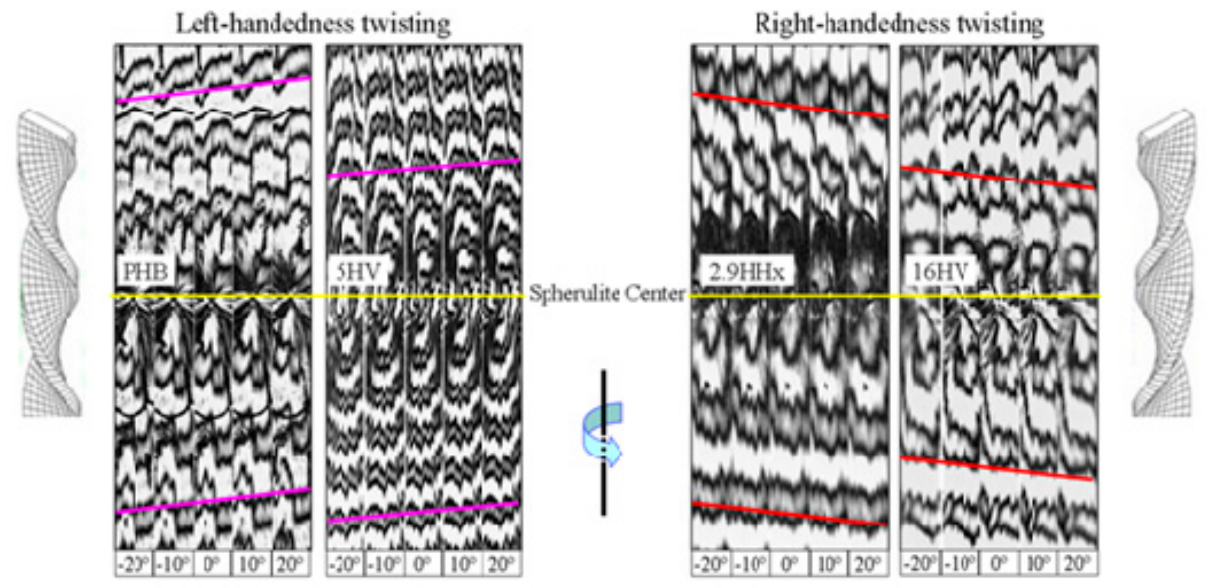

Figure 3. Tilting banded spherulites around an axis on the sample stage under POM reveals twisting handedness of the lamellar crystals. The lamellar twisting handedness in the spherulites of PHB and PHBV with $5 \mathrm{~mol} \% \mathrm{HV}$ comonomers is left-handed and that in PHBHHx with $2.9 \mathrm{~mol} \% \mathrm{HHx}$ comonomers and PHBV with $16 \mathrm{~mol} \% \mathrm{HV}$ comonomers is right-handed. Adapted with permission from Ref. [15]. Copyright (2010) American Chemical Society. 


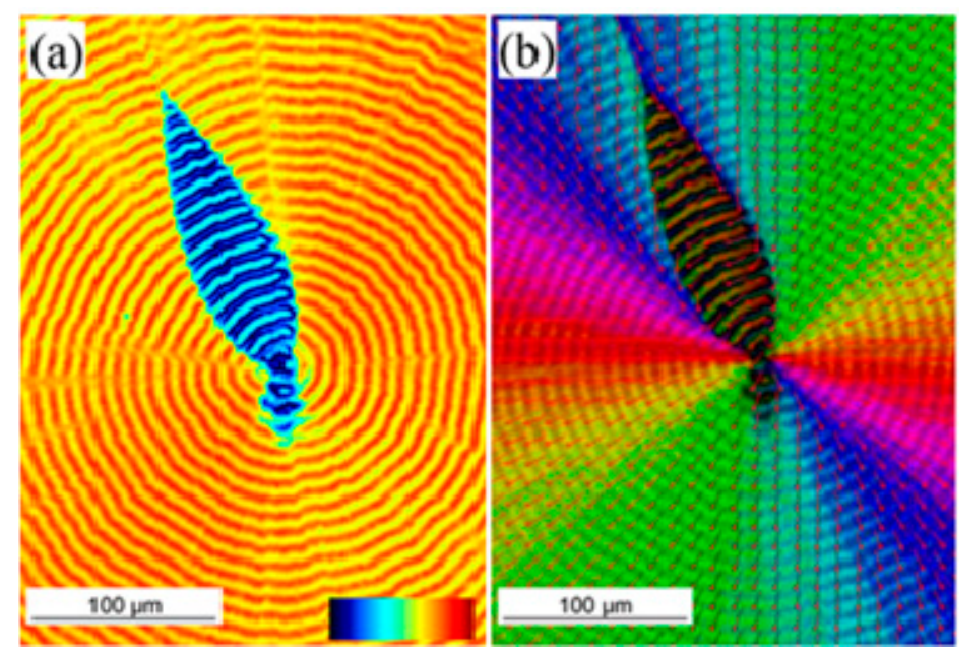

Figure 4. Polscope images of a poly(R-3-hydroxyvalerate) spherulite: (a) Magnitude of birefringent retardance, which is given as pseudo-color. Thicker film and larger crystal birefringence leads to higher retardation. Red corresponds to $273 \mathrm{~nm}$ retardance and black corresponds to zero birefringence. (b) Orientation of the slow optical axis (corresponding to the largest refractive index of the crystal in the film plane) in each location, which is typically shown by short lines for every 15 pixels in the horizontal and vertical direction of the original video frame. Reprinted with permission from Ref. [17]. Copyright (2009) American Chemical Society.

\subsection{Real Time Atomic Force Microscopy (AFM) Observation Reveals Details of Lamellar Twisting}

Previous SEM [20,21], TEM [22,23], and AFM observations [24-26] have demonstrated that the banded polymer spherulites consist of alternative edge-on and flat-on oriented lamellar crystals. However, due to the close packing of the dense lamellae, the lamellar twisting details had not been clearly revealed before the real-time AFM observations [27]. Growth and twisting of the lamellar crystals in the banded spherulites of poly( $R$-3-hydroxybutyrate-co-17 $\mathrm{mol} \%$ R-3-hydroxyhexanoate) (PHBHHx) in a thin film with thickness around $100 \mathrm{~nm}$ is shown in Figure 5. The lamellar crystals changed the orientation from edge-on orientation to tilted (Lamella 1 in Figure 5b and lamella 2 and 3 in Figure 5c), then to flat-on (Figure 5d), via twisting. In this random copolymer, lamellar branching occurs via macro screw dislocations (Label S1 and S2 in Figure 5e,f). It is of particular interest that the fine details of lamellar twisting could only be clearly revealed just at the moment or shortly after the twisting happened (Figure $5 b, c)$. With elapsed time, the trace of twisting was hidden by the over-grown neighboring lamellae (Figure $5 \mathrm{~d}-\mathrm{f}$ ). This might lead to the illusion that the lamellae should twist abruptly when the surface of the completely crystallized banded spherulites were observed under AFM. When the crystallization temperature was further raised, individual continuously twisting lamellae were observed due to the decreased nucleation density, as shown in Figure 6. Twisting could occur before macro screw dislocations were observed (Figure $6 c, d$ ). Consequently, macro screw dislocations were not the cause of lamellar twisting. To confirm that lamellar twisting happened in thick film as well, the lamellar twisting was observed in the film with thickness about $10 \mu \mathrm{m}$ (Figure 7). 

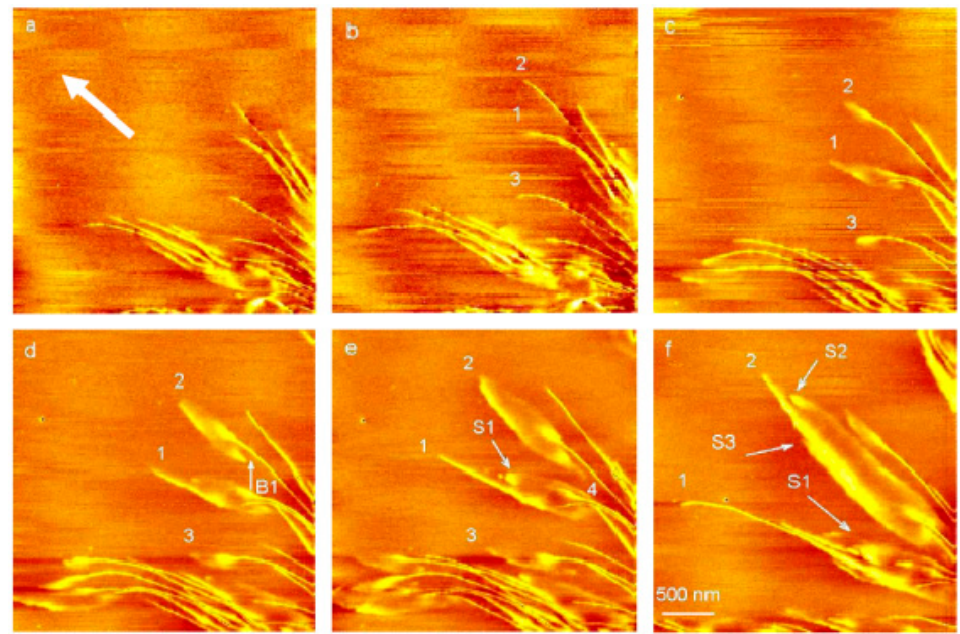

Figure 5. Real-time AFM phase images showing lamellar twisting process of poly $(R-3$-hydroxybutyrateco- $17 \mathrm{~mol} \% \mathrm{R}$-3-hydroxyhexanoate) at $75{ }^{\circ} \mathrm{C}$. The images in (b-f) correspond to elapsed time of 6,12 , 18,24 , and $36 \mathrm{~min}$, respectively, with respect to the first image (a). The arrows labeled with $\mathrm{S}$ indicate macro screw dislocations and B points to backward growth. Adapted with permission from Ref. [27]. Copyright (2004) American Chemical Society.
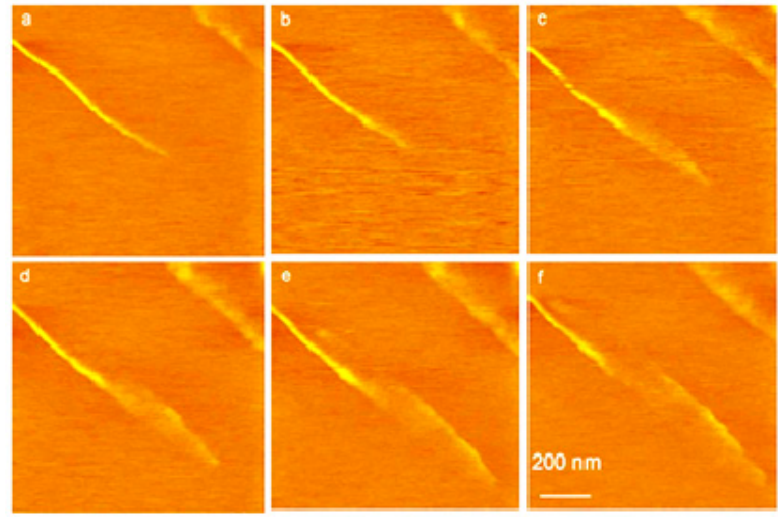

Figure 6. Real-time AFM phase images showing continuous lamellar twisting of poly( $R$-3-hydroxybutyrateco-17 mol \% R-3-hydroxyhexanoate) from edge-on to flat-on at $85{ }^{\circ} \mathrm{C}$. The time intervals between two consecutive images of (a-f) are $6 \mathrm{~min}$. Adapted with permission from Ref. [27]. Copyright (2004) American Chemical Society.

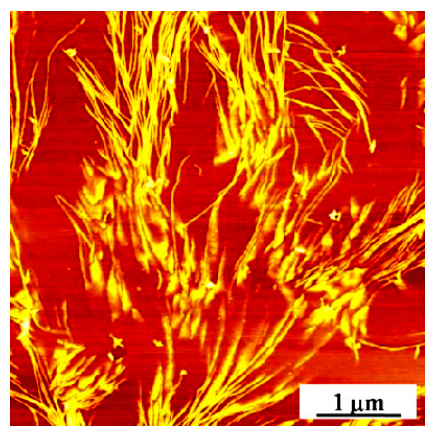

Figure 7. Lamellar twisting of poly( $R$-3-hydroxybutyrate-co- $17 \mathrm{~mol} \% R$-3-hydroxyhexanoate) in a thick film with thickness about $10 \mu \mathrm{m}$. Adapted with permission from Ref. [15]. Copyright (2010) American Chemical Society. 
We should emphasize that the surface morphology of the completely crystallized banded spherulites may not tell the true story. For example, AFM observation on the surface of a completely crystallized PHBHHx banded spherulite seems to indicate the change of growth direction from radial to the tangential direction, as presented in Figure 8. However, it is not the truth. Some other factors may also obscure the trace of twisting and lead to misinterpretation, such as frequent branching of the lamellae and bending of some lamellae with asymmetric shape (e.g., half lamellae).

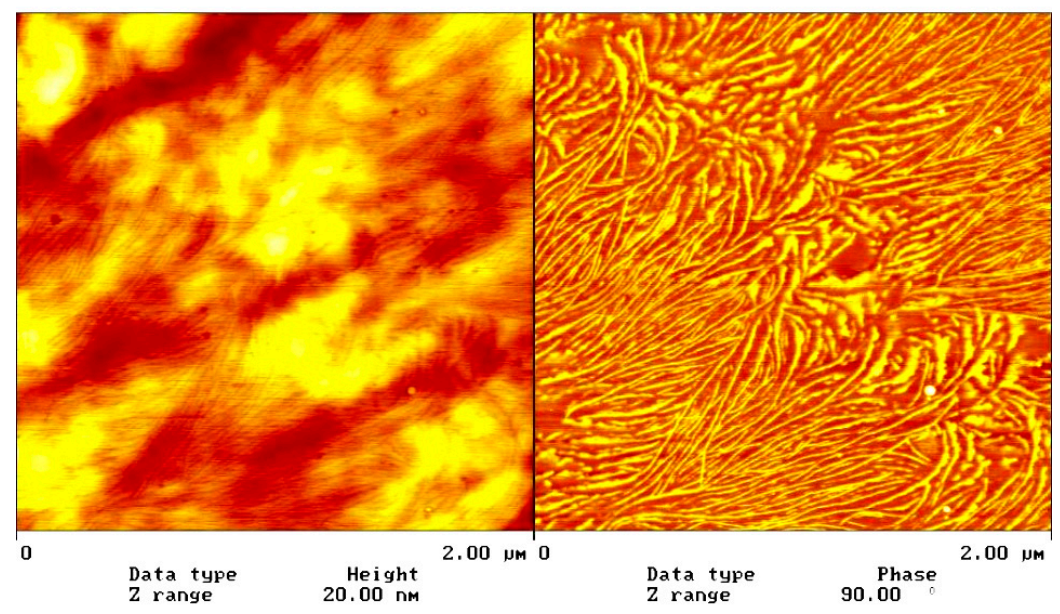

Figure 8. AFM height (left) and phase image (right) of the surface of a part of PHBHHx banded spherulite completely crystallized at $45^{\circ} \mathrm{C}$. Adapted with permission from Ref. [27]. Copyright (2004) American Chemical Society.

Besides the aforementioned techniques, some other tools have been applied to confirm lamellar twisting in the banded spherulites. Micro-focus X-ray diffractograms of polyethylene [28], PLLA [29], PHB [30], poly(E-caprolactone) (PCL)/poly(vinyl butyral) (PVB) blend [31], PHBV blending with amorphous poly(vinyl acetate) (PVAc) [32], and poly(trimethylene terephthalate) (PTT) [33,34] provide additionally direct and firm support that the lamellar crystals twist in the banded spherulites. Micro-FTIR imaging [35-38], nanoindentation [39], and AFM force-volume images [40] can all demonstrate the different orientations of lamellar crystals in the banded spherulites.

Etching of banded polymer spherulites with solvent has been applied to separate the twisting lamellae [41]. The study provided firm support that the banded spherulite consisted of twisting lamellar crystals, while radiating from the spherulite center to the periphery.

In Figure 9, the same radial growth rates of the banded spherulites in the bright and dark bands preclude the possibility of remarkable change of the fast growth axis of the lamellar crystals along the radial direction [42].

Besides banded polymer spherulites, the banded spherulites of small molecules, such as $\mathrm{K}_{2} \mathrm{Cr}_{2} \mathrm{O}_{7}$ [43], hippuric acid [44], and aspirin [45], are composed of twisted crystals as well.

In the past decade, Woo et al. [46-48] has studied the surface and cross section morphology of banded spherulites in fractured films of various polyesters. Based on these morphology observations, he questioned the mechanism of lamellar twisting in these banded spherulites and proposed the scheme of alternative radial and tangential growth of lamellar crystals. The work has stimulated new open discussions. Since the special issue provides a valuable platform for exchange of ideas, we would like to discuss it here. Though the scheme is posed based on some experimental observations, it is difficult to accommodate the following questions and experimental results: (1) How can the radially grown lamellar crystals initiate growth of the next layer tangential lamellae? It is difficult for the information of growing along the radius and then turning to the tangential direction to transfer from the spherulite center to periphery without disruption and while keeping the band spacing constant; (2) This scheme should lead to considerably different radial growth rates of the bright and dark bands 
in the spherulites, which has not been observed experimentally; (3) Tilting of the sample should not shift the bands according to the scheme. Consequently, the scheme of alternative radial and tangential lamellae does not agree with the previous experimental results of our lab and other groups.

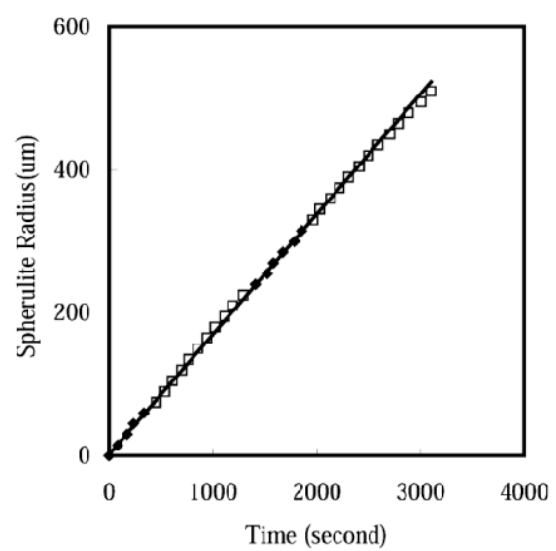

Figure 9. Growth profile of a PLLA banded spherulite crystallized at $135^{\circ} \mathrm{C}$ showing the almost same radial growth rate of the bright and dark bands. The open data points indicate the bright bands and the closed points indicate the dark bands. Reprinted with permission from Ref. [42]. Copyright (2005) Elsevier, Ltd.

\section{Organization of Twisted Lamellae in Banded Spherulites}

Banded spherulites consist of twisting lamellae, however, the scheme that banded spherulites consisting of many individual twisting lamellae is over-simplified. To form regular bands with uniform band spacing, two conditions are necessary: One is that the twisting information and the twisting sense should be transferred without disruption during growth of the lamellar crystals. The other requires synchronous twisting, namely, the neighboring twisting lamellae along the tangential direction should take similar (not much different) orientation at the same radial distance, as shown in Figure 10. In Figure 10d, it seems that the lamella twist abruptly from edge-on to flat-on orientation. However, from Figure 10a-c, the lamella twist smoothly to change the orientation, as indicated by the arrow. The feeling of abrupt twisting from Figure 10d is due to the complicated curvature of the lamella, as schemed in Figure 11. In Figure 11a, the edge-on lamella slightly twists to the tilted orientation at point A. In addition, the lamella scrolls along the tangential direction as well. As a result, the orientation at point $A$ is totally different from that at point $B$, which leads to the illusion that the lamella twists abruptly. In fact, the lamella curves smoothly, as shown in Figure 11d.

We have proposed a mechanism leading to the cooperative packing of the twisting lamellae, as schemed in Figure 12 [49]. The leading edge-on lamella twists to adopt flat-on orientation (Frame 1 to 3). With further growth and twisting, the flat-on lamella twists to form tilted lamella (Frame 4). At the same time, screw dislocations (which may be exaggerated by twisting) produce several daughter lamellae with similar orientation. These daughter lamellae further grow and twist to edge-on lamellae. Namely, the screw dislocations lead to similar orientation of the neighboring lamellae, providing a mechanism for lamellar branching and synchronous twisting. When crystallized at high temperatures, the frequency of screw dislocations decreases. This leads to poor cooperative packing of twisting lamellae and probably results in the irregular banded structure at high temperatures. Toda et al. [50-52] have systematically revealed the role of macro screw dislocations in lamellar branching in the banded polymer spherulites.

The bright and gray bands of PHB spherulites observed under POM correspond to the edge-on and flat-on orientation of the twisted lamellae, namely, the edge-on lamellae possess higher birefringent retardation than the flat-on lamellae. For PHB banded spherulite, $a$ (along spherulite radius) [30,53], $b$ (tangential), and $c$ (chain direction) axis of the crystal lattice corresponds to the $\mathrm{n}_{2}, \mathrm{n}_{3}$ and $\mathrm{n}_{1}$ optical 
axes (with the definition $n_{3}>n_{2}>n_{1}$ ) [14]. $\left|n_{2}-n_{1}\right|$ of the edge-on lamellae is larger than $\left|n_{3}-n_{2}\right|$ of the flat-on lamellae, which results in the wider bright bands with positive birefringent retardation and the narrower gray bands with negative retardation. Previous assignment [53] that the $b$ axis is along the bright bands is wrong. It should be the $c$ axis that is along the bright bands, which correspond to edge-on oriented lamellae.

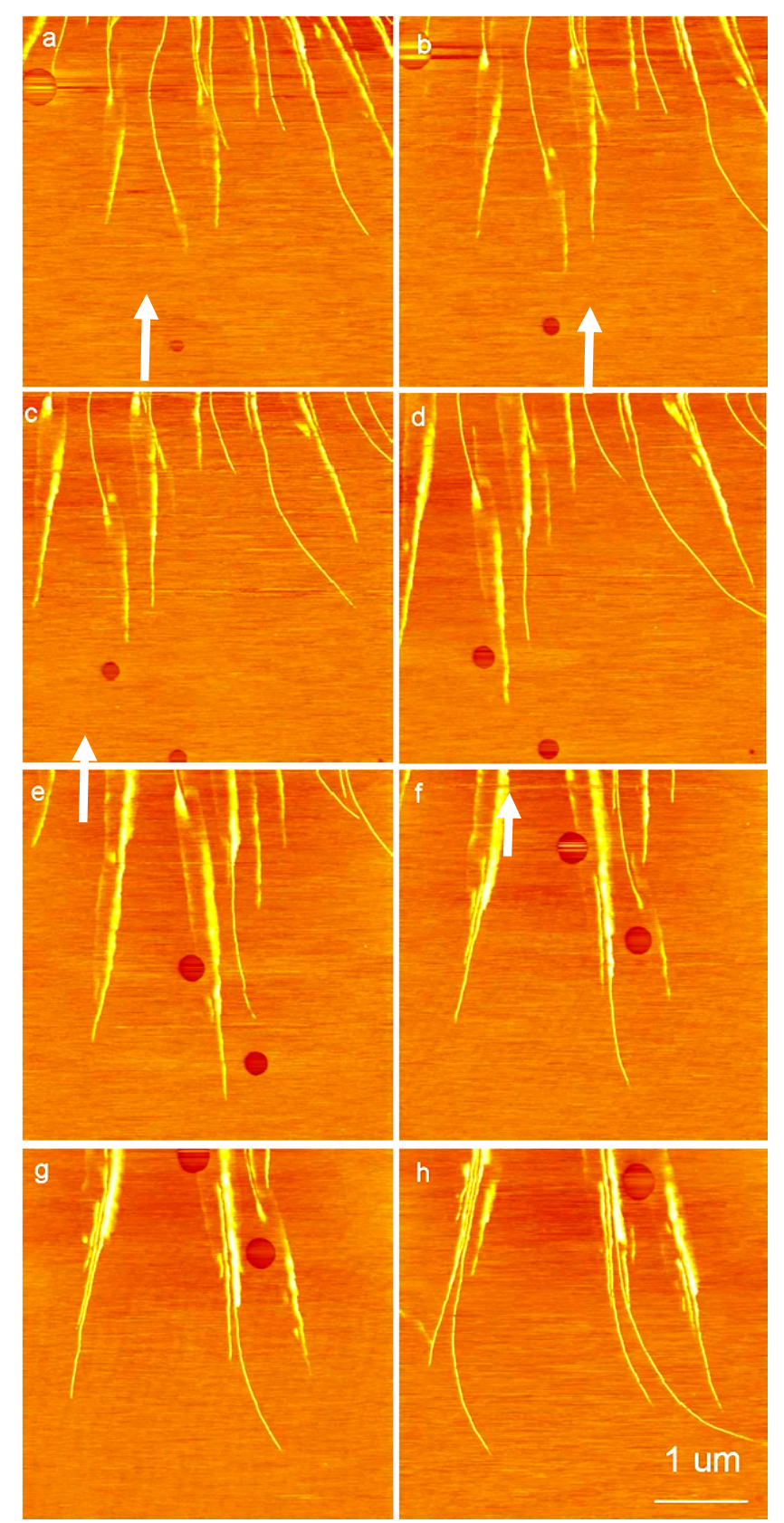

Figure 10. Real-time AFM phase images showing the lamellar twisting process and the consecutive right-handed macro screw dislocations caused by lamellar twisting in poly( $R$-3-hydroxybutyrate-co- 17 mol \% R-3-hydroxyhexanoate) crystallized at $85^{\circ} \mathrm{C}$. The images in $(\mathbf{b}-\mathbf{h})$ correspond to elapsed times of $17,25,68,93,119,161$, and $212 \mathrm{~min}$, respectively, with respect to the first image (a). Reprinted with permission from Ref. [49]. Copyright (2007) Elsevier, Ltd. 

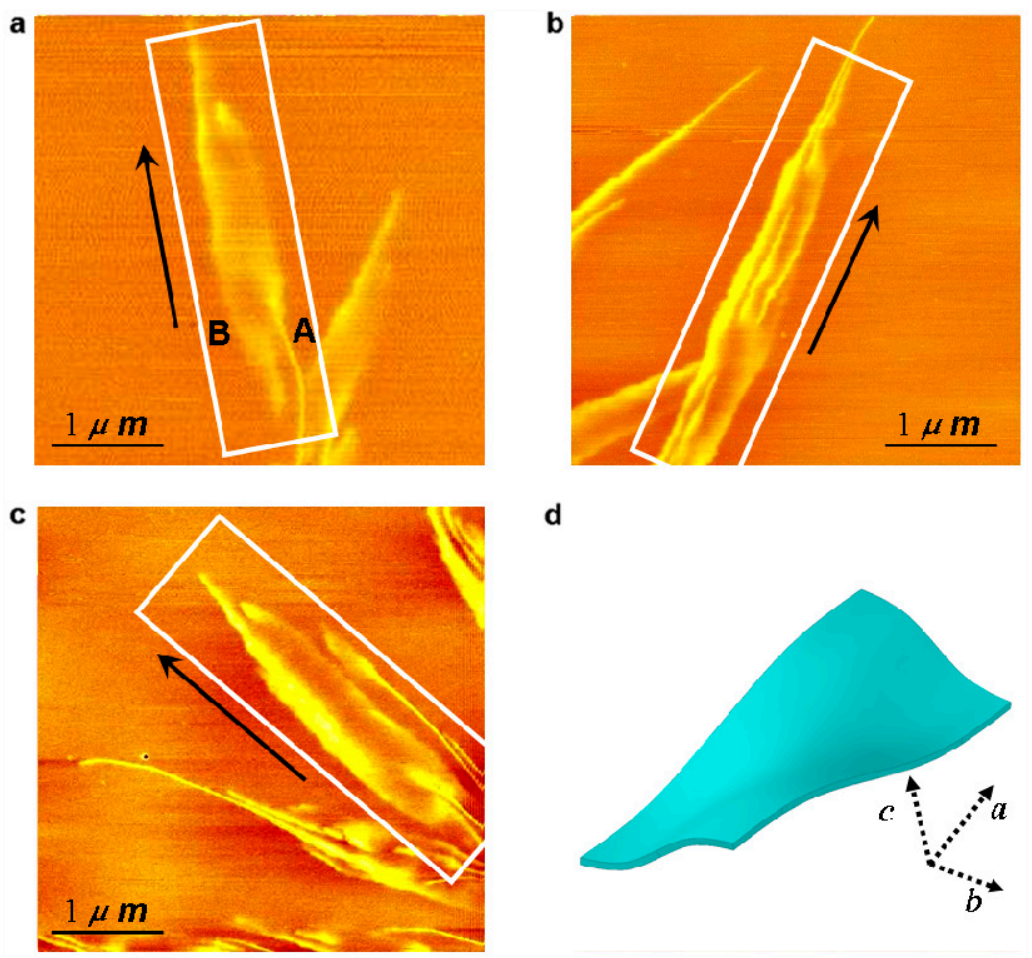

d

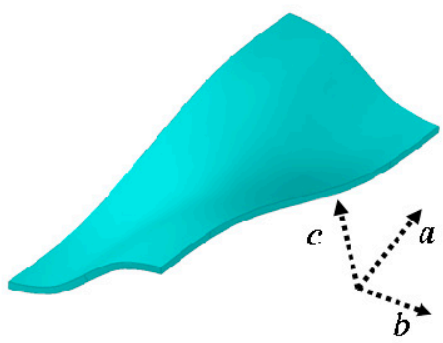

Figure 11. AFM images (a-c) and the scheme (d) showing the curvature of the lamella of PHBHHx crystallized at $75^{\circ} \mathrm{C}$. The $a, b$, and $c$ axes are also the three $\mathrm{C}_{2}$ axes of the lamella curvature. The arrows indicate the radial growth direction ( $a$ axis) and the rectangular frames indicate the lamella with complicated curvature, which shows $S$ and anti-S profile when viewed against the radial growth direction and the tangential direction, respectively. Namely, it is a double twisted lamella. Adapted with permission from Ref. [15]. Copyright (2010) American Chemical Society.

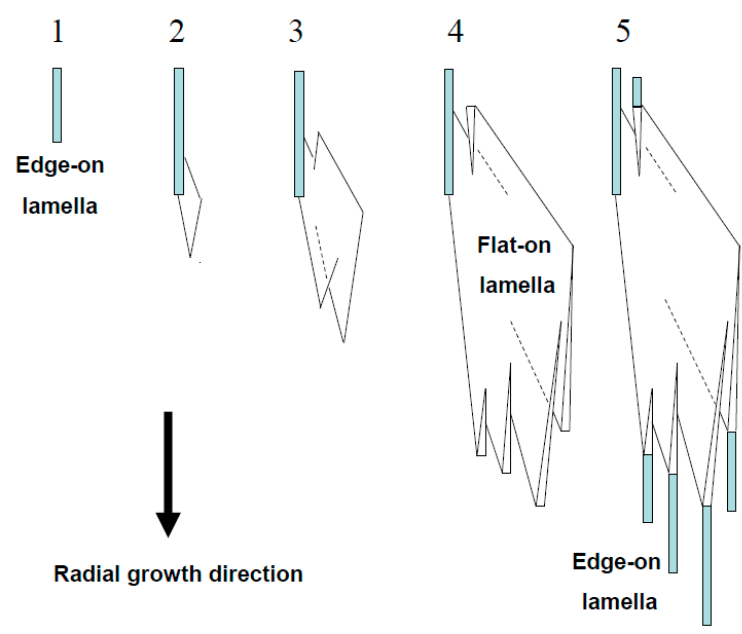

Figure 12. Scheme showing the details of growth and organization of the twisted lamellar crystals. The lamellar crystals change orientation via twisting. Macro screw dislocations lead to multiplication of lamellar crystals and synchronous twisting of neighboring lamellae. Redrawn with permission from Ref. [49]. Copyright (2007) Elsevier, Ltd.

In PHV banded spherulite, a special morphology containing an eye-like or tear-drop shaped region with mixed positive and negative birefringence surrounded by a normal region with positive birefringence could be observed [17]. Both the two types of regions correspond to the same crystal lattice. However, the lamellar crystals in the two regions grow along the different crystal axes. In the 
eye-like region, the $a$ axis of the lamellar crystal is along the radial direction, while in the normal positive birefringent region, the $b$ axis lies in the radial direction of the banded spherulite, as revealed in Figure 13. Tilting experiments demonstrated that the lamellar crystals exhibited the opposite twisting handedness along the different growth axes in the two regions. This observation challenges the previous belief that the lamellar crystals in the banded spherulites of a non-racemic chiral polymer should show a certain defined twisting handedness [54]. The special eye-like POM morphology in spherulites has been reported in poly(ethylene adipate) (PEA) [55], isotactic polypropylene (iPP) [56], poly(ethylene succinate) (PES) [57], and cellulose/ionic liquid spherulites [58].

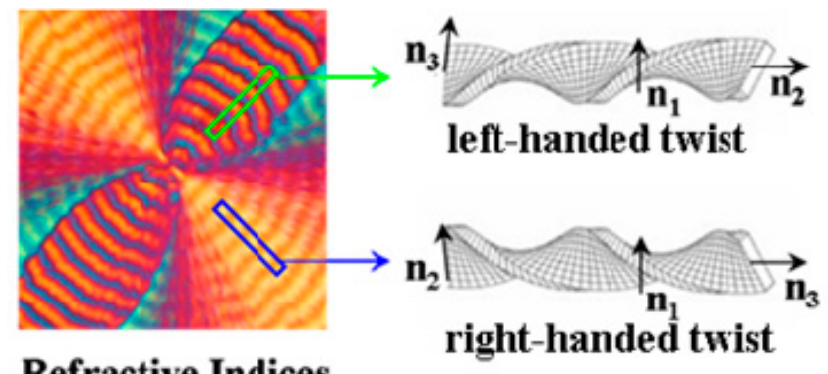

Refractive Indices

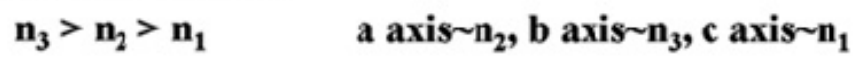

Figure 13. Scheme of the two radial growth directions and twist senses in the normal region and the eye-like region of the PHV spherulite. In the eye-like region, the radial direction is along the $a$ axis with left-handed lamellar twisting. In the other region, the radial direction is along the $b$ axis with right-handed twisting. Adapted with permission from Ref. [17]. Copyright (2009) American Chemical Society.

The bright and gray bands of PHB and poly(R-3-hydroxybutyrate-co-10 mol \% $R$-3-hydroxyvalerate) under POM are the ridge and valley regions in the AFM height image, respectively [40]. It is the usual case for most banded spherulites. However, it is the opposite in the banded spherulites of poly(R-3-hydroxybutyrate-co-17 mol \% R-3-hydroxyhexanoate), in which the bright POM bands consisted of edge-on lamellae in the valley region in the AFM height image. The surface height fluctuation of the two types of birefringent polymer banded spherulite is in the order of tens of nanometers, less than $1 \%$ of the film thickness. In contrast, in the nonbirefringent banded spherulites formed from all flat-on lamellar crystals, the height fluctuation is up to the whole thickness of the sample [1-3].

In some cases, banded spherulites with spiral bands can be observed. There are two possibilities: One is that the spirals really exist, which can be confirmed by SEM or AFM observation of the surface morphology [59]. The other is due to the artifact of polarized light. When the twisted lamellar crystals growing synchronously from the spherulite center are parallel to the glass slide, the concentric bands will be observed under cross polarized microscope. If the twisted lamellar crystals are tilted to the glass slide, spiral bands will be observed under POM [11-14]. The spiral sense depends on both the sign of the tilt angle and the handedness of lamellar twisting, as shown by the simulated morphology in Figure 14. The experimental results in Figure 15 confirm the simulated morphology [14].

Recently, micro-focus WAXD results show that poly(propylene adipate) (PPA) banded spherulites consisted of helically rather than helicoidally twisted lamellae [60]. The simulated POM pattern in Figure 1 agrees with the experimentally captured micrograph. 


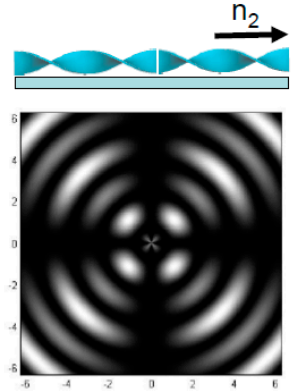

(a)

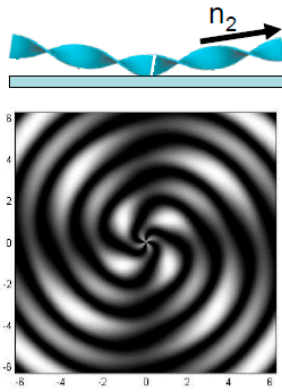

(b)

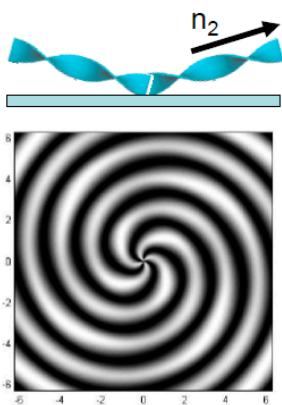

(c)

Figure 14. Simulated POM pattern of a spherulite consisting of twisted lamellar crystals with biaxial birefringence. The tilting angle of the lamellar crystals toward the glass slide is $(\mathbf{a}) 0^{\circ}$; (b) $15^{\circ} ;$ (c) $30^{\circ}$. The three refractive indices of the crystals are arbitrarily chosen as: $\mathrm{n}_{1}=1.45, \mathrm{n}_{2}=1.5, \mathrm{n}_{3}=1.57$. The $\mathrm{n}_{2}$ axis of the crystals are along the radial direction. The sample thickness is set as six times the wavelength of the transmitted light. Adapted from Ref. [14].

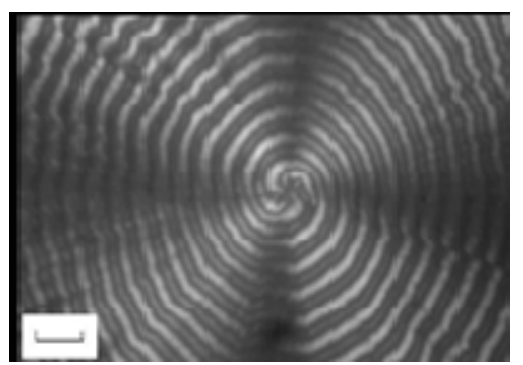

(a)

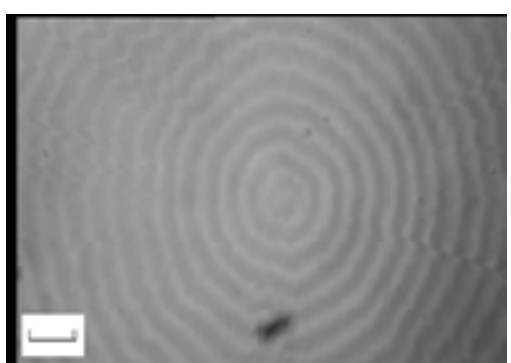

(b)

Figure 15. A PHBV banded spherulite showing spirals under cross polarized optical microscope (a) and concentric bands observed without polarizer and analyzer $(\mathbf{b})$. The scale bar is 10 microns. Adapted from Ref. [14].

\section{Driving Force for Lamellar Twisting in Banded Polymer Spherulites}

In the past decades, the lamellar twisting in banded polymer spherulites has been attributed to several mechanisms, such as surface stresses $[6,7,61]$, screw dislocations $[62,63]$, and external compositional or stress fields [64], etc.

External or internal reason? Since individual twisted lamellar crystals can be isolated from the crystallized samples [41,65], the origin of lamellar twisting should be internal rather than external forces, though the external fields during lamellar growth may affect lamellar twisting to some extent. In addition, the external fields could not guarantee the fixed handedness of twisting during lamellar growth. In the recent review, Crist and Schultz [9] acknowledged: "There is general agreement that the kinetic field model does not account for banding in polymer spherulites."

Screw dislocations or other factors? Keith and Padden [6] have ruled out the possibility that macro screw dislocations led to lamellar twisting in banded polymer spherulites. Our real-time AFM observation on lamellar twisting of individual lamellae clearly demonstrated that screw dislocation is the consequence rather than the cause of lamellar twisting [27]. In fact, lamellar twisting happens before appearance of macro screw dislocations. The chiral lamellar twisting leads to consecutive screw dislocations with the same handedness.

Surface or bulk stresses? Surface stresses have long been proposed as the driving force of lamellar twisting. Originally, Hoffman and Lauritzen [61] postulated that the helical lamellar twisting may result from surface stresses. Later, Keith and Padden [6] qualitatively attributed bending of half lamella and helicoidal twisting of the full lamellae of PE and other polymers to unbalanced surface stresses resulting from overcrowding of folds. In 2005, Lotz and Cheng [7] attributed the mechanical origin of 
the lamellar curvature in both achiral and chiral polymers, e.g., bending, twisting, and scrolling, to the unbalanced surface stresses arisen from the different degrees of overcrowding at the two fold surfaces of the lamellar crystals. The molecular origin of the surface stresses was systematically established in the critical review.

However, what determines the twisting handedness of lamellar crystals in the banded spherulites of non-racemic chiral polymers had been a controversy over decades till our study. We observed the opposite chiral senses of the twisting lamellae along the two different growth axes in PHV banded spherulites [17]. This observation violated the previous belief that the lamellar crystals of a chiral polymer should exhibit a certain defined twisting sense. The growth axis-dependent lamellar twisting chirality was attributed to the distribution of the anisotropic surface stresses in the four sectors of a single lamella, as schemed in Figure 16. In each sector, the magnitude of the surface stress on the top surface will be different from that on the bottom surface. In PHB and PHV, both the crystal lattice and the distribution of surface stresses show the symmetry of $\mathrm{P} 2{ }_{1} 2_{1} 2_{1}$. Namely, viewed down the radial growth axis, the two halves of the lamellar crystals show 2-fold rotational symmetry, namely, when the lamella rotates by $180^{\circ}$, the distribution of surface stresses is exactly the same as that before rotation.

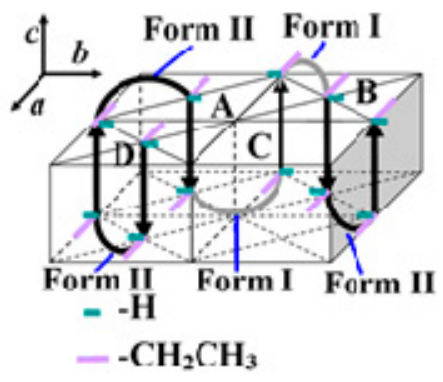

(a) side view

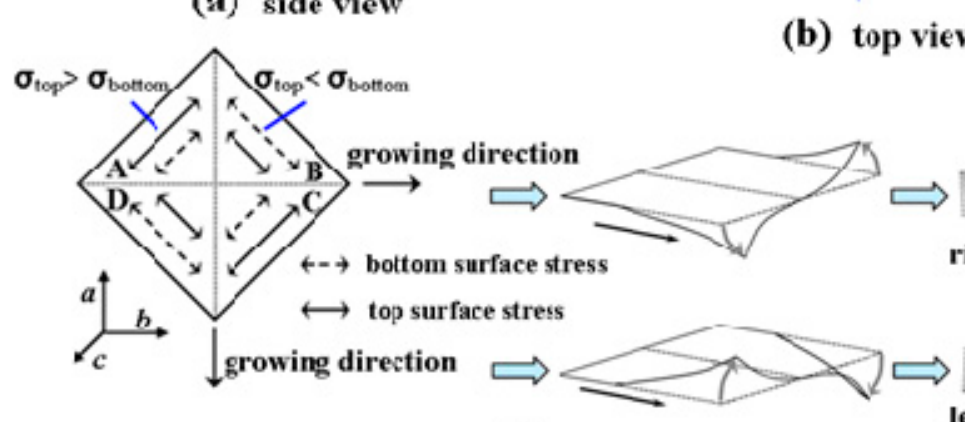

(c)

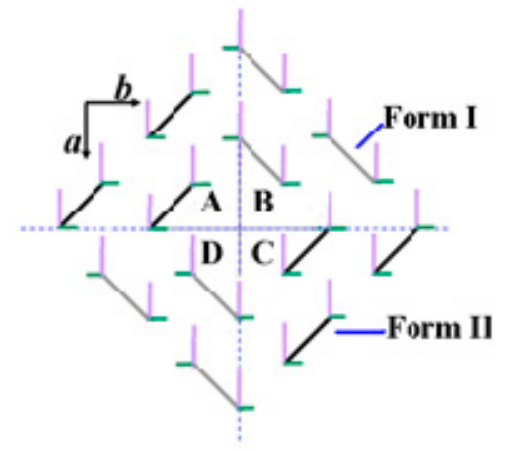

(b) top view

Figure 16. Mechanical model interpreting the origin of the unbalanced anisotropic surface stresses and the resultant opposite twist handedness along the two orthogonal axes of PHV lamella. (a) The side view of the configuration of the chain stems and the folds on the opposite lamellar surfaces of a single lamella, wherein the configurations are simplified according to the symmetry rule that $a, b$, and $c$ axes are the three $2{ }_{1}$ screw axes. A, B, C, and D indicate the four sectors of a lamella. The bold black arrows indicate the helical chain stems with up or down direction. (b) The top view of the folds on the lamellar surface. The folds of form I and those of form II are of different encumbrances. (c) The scheme of lamellar twist sense induced by the unbalanced surface stresses along the two orthogonal growth axes. The twisting lamella scheme is adopted from Ref. [66] and the cooperative behavior of two half lamellae is redrawn from Ref. [6]. Reprinted with permission from Ref. [17]. Copyright (2009) American Chemical Society.

In the field of inorganic crystals and low molecular weight organic crystals, Punin $[67,68]$ and Shtukenberg et al. $[8,69,70]$ proposed that heterometry stress may cause bending and twisting of bulk and meso crystals. The heterometry stress arises from the unequal lattice constants in the different 
growth sectors due to heterogeneous distribution of impurity and defects and may exist in both bulk and surface of the crystals.

Via changing the chemical groups on the amorphous surface of the lamellar crystal of PHB random copolymers and the $\mathrm{PHB} / \mathrm{PHBHHx}$ blends, we could invert the twisting chirality without change of the symmetry of the crystalline lamellar core. With increase of comonomer composition in the random copolymers of PHBV and blends of PHB/PHBHHx, lamellar twisting handedness changed from left to right-handed, as previously shown in Figure 3 [15]. Since the comonomer units are precluded from the crystalline lamellar core and enriched at the amorphous surface, this observation unambiguously reveals that it is the surface rather than the bulk factors that determine the twisting chirality of the studied polymer lamellar crystals.

Collaborating with Jianshan Wang and Xiqiao Feng, the quantitative effect of surface stresses on the lamellar twisting chirality and pitch was simulated [15,71]. The results confirmed that variation of the direction of the principal surface stresses could lead to the inversion of twisting chirality.

The above experimental results and physical models demonstrate that it is the distribution (more precisely, symmetry) of the anisotropic and unbalanced surface stresses that directly determines the twisting chirality of the polymer lamellar crystals. In turn, variation of molecular chirality, growth axis, and surface groups can all affect the surface stresses, thus change the twisting chirality of polymer lamellar crystals. The distribution of surface stresses on the lamellae of chiral and nonchiral polymers is schemed in Figures 17 and 18, respectively. For both the two cases, when lamellar twisting occurs, the surface stress has a $C_{2}$ rotation axis along the radial growth direction. Lamella of chiral polymers exhibits the same twisting handedness viewed from the two ends, while that of nonchiral polymers shows the opposite twisting chirality in the two growth directions.

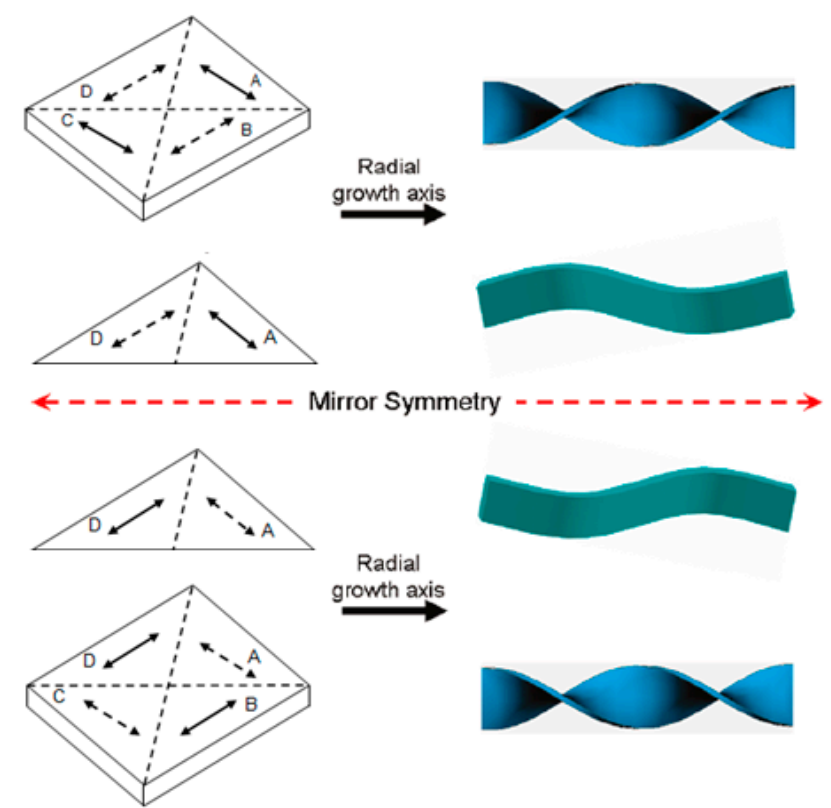

Figure 17. Effect of molecular chirality on the distribution of surface stresses and the corresponding chirality of lamellar curvature. The black solid and dashed arrows indicate the net tensile stress on the top and bottom surface of the lamella, respectively. Adapted with permission from Ref. [15]. Copyright (2010) American Chemical Society. 

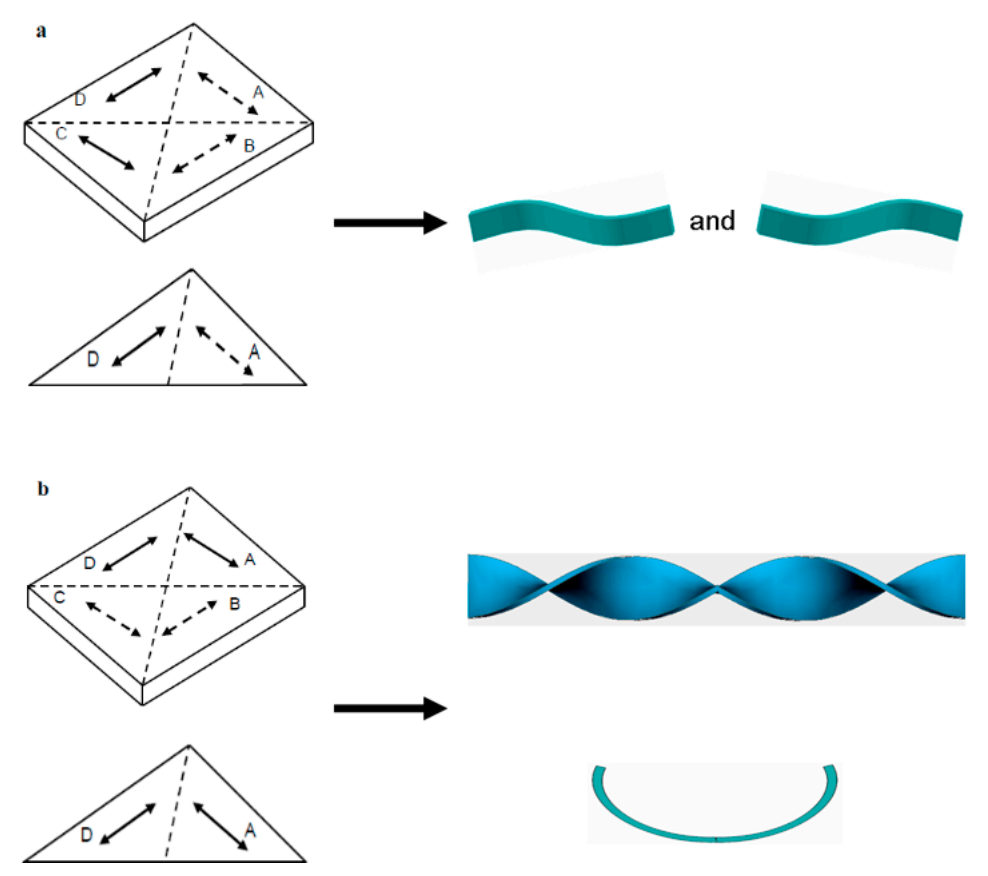

Figure 18. Two possible distributions of surface stresses in lamella of nonchiral polymers. The black solid and dashed arrows indicate the net tensile stress on the top and bottom surface of the lamella, respectively. The case (b) rather than the case (a) leads to lamellar twisting. Adapted with permission from Ref. [15]. Copyright (2010) American Chemical Society.

\section{Factors Affecting Band Spacing}

Both chemical composition and crystallization conditions affect the band spacing of banded spherulites. Band spacing usually increases with rising crystallization temperature [69]. Considering both the variation of the bending curvature of PHBHHx half lamellar crystals and the lamellar thickness with supercooling, we qualitatively estimated the variation of surface stresses of PHBHHx with supercooling [15], which indicated that the surface stresses increased with rising supercooling. However, there are at least two exceptions. One is that two types of banded spherulites of poly(butylene adipate) (PBA) demonstrated decreasing band spacing with rising temperature [72]. The other is that poly(trimethylene terephthalate) (PTT) banded spherulites exhibited decreasing banding spacing with increasing temperature in a certain temperature range [73].

At present, it is still a great challenge to quantitatively measure the surface stresses on the polymer lamellar crystals with thickness of only several nanometers. Mechanical simulation shows that lamellar shape and size considerably affect the lamellar curvature [15,71]. With increasing lamellar thickness, the twisting pitch becomes larger providing the same surface stresses [71].

Mixing with other components also has considerable effect on the band spacing [74], implying that the amplitude of surface stresses is probably changed. For instance, when blended with another polymer, the band spacing of PLLA spherulite became smaller [42]. We should point out that our study demonstrated that pure PLLA polymer itself can form banded spherulites [42], though blending with other components might accelerate lamellar twisting and enhance the regularity of bands. This also stands for PCL [75-78]. Recently, Ho et al. [79] reported that chiral dopants can tune the twisting chirality of lamellar crystals of nonchiral isotactic poly(2-vinylpyridine), where $(R)$ - and $(S)$-hexahydromandelic acid dopant induced right-handed and left-handed lamellar twisting, respectively. 


\section{Conclusions and Perspective}

Combining various characterization techniques and physical modelling, we demonstrate that the birefringent banded polymer spherulites consist of twisting lamellar crystals. The fine details of lamellar twisting in the banded spherulites was revealed for the first time by real-time AFM observation during growth of PHBHHx spherulites from thin melt film. Continuous twisting leads to change of lamellar orientation from edge-on to flat-on, then to edge-on again. Chiral twisting could occur before appearance of macro screw dislocations. The successive macro screw dislocations with the same handedness are a consequence rather than the cause of the chiral lamellar twisting. However, the macro screw dislocations give birth to multiple daughter lamellae with similar orientation, which provides a most probable mechanism for cooperative packing of neighboring twisted lamellar crystals and thus formation of regular bands.

The driving force for twisting of polymer lamellar crystals has long been attributed to unbalanced surface stresses. Based on both experimental findings and physical modeling, we reveal that it is the distribution of anisotropic and unbalanced surface stresses that directly determines the handedness of lamellar twisting. Besides molecular chirality, variation of growth axis and the amount of bulky groups on the surfaces can invert the handedness of lamellar twisting. This explains why the previous attempts to correlate lamellar twisting chirality with molecular chirality inevitably failed. The distribution of surface stresses is a bridge from molecular chirality to crystal chirality for twisted polymer lamellae.

Many factors will affect the pitch of lamellar twisting, thus the band spacing of spherulites, including lamella thickness and the principal direction and magnitude of surface stresses. These factors are influenced by crystallization conditions and the chemical composition of the polymer system. Usually, band spacing arises with increasing crystallization temperature. Nonetheless, there are exceptions, where band spacing decreases with rising temperature. Mixture with other components often leads to regular bands and decreasing band spacing.

Twisting lamellar crystals may possess optical activity, such as circular birefringence [80], circular dichroism [81], and second harmonic generation [82], etc. Consequently, polymer banded spherulites may find potential applications in optical devices.

There are still some challenges and questions remaining in the field of polymer banded spherulites. How to precisely determine the distribution and magnitude of surface stresses? Does bulk stress contribute to lamellar curvature? Is the twist totally elastic or with partially plastic deformation? How does blending affect the band spacing? Does lamellar twist occur at the growth front or happen after solidification of the crystal? Answers to these open questions need further study, probably with the aid of new insights and novel techniques.

Acknowledgments: We thank the collaborators very much. The work could not be fulfilled without the collaboration with George Guoqiang Chen, Lin Li, Xiqiao Feng, Tadahisa Iwata, Ping Xue, Hui Ma and Bart Kahr. Jianjun Zhou helped carry out part of the AFM characterization work and Jianshan Wang simulated the mechanics behavior of lamellar crystals under surface stresses. Jun $\mathrm{Xu}$ is deeply grateful to Bernard Lotz for fruitful discussions and valuable comments. The authors are indebted to the National Natural Science Foundation of China (Grant No. 20504019, 20974060, 21374054), the Sino-German Center for Research Promotion (Grant No. GZ 833) and Fund of Key Laboratory of Advanced Materials of Ministry of Education No. 2017AML07 for financial support.

Author Contributions: Jun Xu conducted the main research and wrote the manuscript. Haimu Ye carried out the main experimental work in this review. Shujing Zhang wrote a part of the manuscript and formatted the manuscript. Baohua Guo proof-red and revised the manuscript.

Conflicts of Interest: The authors declare no conflict of interest. The founding sponsors had no role in the design of the study; in the collection, analyses, or interpretation of data; in the writing of the manuscript, and in the decision to publish the results.

\section{References}

1. Duan, Y.; Jiang, Y.; Jiang, S.; Li, L.; Yan, S.; Schultz, J.M. Depletion-induced nonbirefringent banding in thin isotactic polystyrene thin films. Macromolecules 2004, 37, 9283-9286. [CrossRef] 
2. Wang, Z.; Hu, Z.; Chen, Y.; Gong, Y.; Huang, H.; He, T. Rhythmic growth-induced concentric ring-banded structures in poly( $\varepsilon$-caprolactone) solution-casting films obtained at the slow solvent evaporation rate. Macromolecules 2007, 40, 4381-4385. [CrossRef]

3. Li, Y.; Wang, Z.; He, T. Morphological control of polymer spherulites via manipulating radial lamellar organization upon evaporative crystallization: A mini review. Crystals 2017, 7, 115. [CrossRef]

4. Kwiatkowski, M.; Hinrichsen, G. A new banded texture in sheared thermotropic liquid crystalline polymers. J. Mater. Sci. 1990, 25, 1548-1550. [CrossRef]

5. Ding, J.; Feng, J.; Yang, Y. Sinusoidal supermolecular structure of band textures in a presheared hydroxypropyl cellulose film. Polym. J. 1995, 27, 1132-1138. [CrossRef]

6. Keith, H.D.; Padden, F.J. Twisting orientation and the role of transient states in polymer crystallization. Polymer 1984, 25, 28-42. [CrossRef]

7. Lotz, B.; Cheng, S.Z.D. A critical assessment of unbalanced surface stresses as the mechanical origin of twisting and scrolling of polymer crystals. Polymer 2005, 46, 577-610. [CrossRef]

8. Shtukenberg, A.G.; Punin, Y.O.; Gujral, A.; Kahr, B. Growth actuated bending and twisting of single crystals. Angew. Chem. Int. Ed. 2014, 53, 672-699. [CrossRef] [PubMed]

9. Crist, B.; Schultz, J.M. Polymer spherulites: A critical review. Prog. Polym. Sci. 2016, 56, 1-63. [CrossRef]

10. Bolotov, I.E.; Kolosov, V.Y.; Kozhyn, A.V. Electron microscope investigation of crystals based on bend-contour arrangement II. Bending phenomena of the crystal growth in an amorphous film. Phys. Status Sol. A 1982, 72, 645-654. [CrossRef]

11. Keith, H.D.; Padden, F.J. The optical behavior of spherulites in crystalline polymers. Part I. Calculation of theoretical extinction patterns in spherulites with twisting crystalline orientation. J. Polym. Sci. 1959, 39, 101-102. [CrossRef]

12. Price, F.P. On extinction patterns of polymer spherulites. J. Polym. Sci. 1959, 39, 139-150. [CrossRef]

13. Keller, A. Investigations on banded spherulites. J. Polym. Sci. 1959, 39, 151-173. [CrossRef]

14. $\mathrm{Xu}, \mathrm{J}$. Study on Tailor-Design of Polyhydroxyalkanoates and Crystallization Mechanism of Their Banded Spherulites. Ph.D. Thesis, Tsinghua University, Beijing, China, 2002. (In Chinese)

15. Ye, H.M.; Wang, J.S.; Tang, S.; Xu, J.; Feng, X.Q.; Guo, B.H.; Xie, X.M.; Zhou, J.J.; Li, L.; Wu, Q.; et al. Surface stress effects on the bending direction and twisting chirality of lamellar crystals of chiral polymer. Macromolecules 2010, 43, 5762-5770. [CrossRef]

16. Oldenbourg, R.; Mei, G. New polarized light microscope with precision universal compensator. J. Microsc. 1995, 180, 140-147. [CrossRef] [PubMed]

17. Ye, H.M.; Xu, J.; Guo, B.H.; Iwata, T. Left- or right-handed lamellar twists in poly[(R)-3-hydroxyvalerate] banded spherulite: Dependence on growth axis. Macromolecules 2009, 42, 694-701. [CrossRef]

18. Kahr, B.; Freudenthal, J.; Gunn, E. Crystals in light. Acc. Chem. Res. 2010, 43, 684-692. [CrossRef] [PubMed]

19. Guo, Y.; Zeng, N.; He, H.; Liu, C.; Du, E.; He, Y.; Ma, H. Retardance of bilayer anisotropic samples consisting of well-aligned cylindrical scatterers and birefringent media. J. Biomed. Opt. 2016, 21, 055002. [CrossRef] [PubMed]

20. Eppe, R.; Fischer, E.W.; Stuart, H.A. Morphologische strukturen in polyäthylenen, polyamiden und anderen kristallisierenden hochpolymeren. J. Polym. Sci. 1959, 34, 721-740. [CrossRef]

21. Wang, Z.; An, L.; Jiang, W.; Jiang, B.; Wang, X. Ring-banded spherulite surface structure of poly( $\varepsilon$-caprolactone) in its miscible mixtures with poly(styrene-co-acrylonitrile). J. Polym. Sci. Part B Polym. Phys. 1999, 37, 2682-2691. [CrossRef]

22. Ho, R.M.; Ke, K.Z.; Chen, M. Crystal structure and banded spherulite of poly(trimethylene terephthalate). Macromolecules 2000, 33, 7529-7537. [CrossRef]

23. Vaughan, A.S. Etching and morphology of poly(vinylidene fluoride). J. Mater. Sci. 1993, 28, $1805-1813$. [CrossRef]

24. Cramer, K.; Lima, M.F.S.; Magonov, S.N.; Hellmann, E.H.; Jacobs, M.; Hellmann, G.P. Atomic force microscopy on tree-like crystals in polyvinylidene fluoride blends. J. Mater. Sci. 1998, 33, 2305-2312. [CrossRef]

25. Hobbs, J.K.; McMaster, T.J.; Miles, M.J.; Barham, P.J. Direct observations of the growth of spherulites of poly(hydroxybutyrate-co-valerate) using atomic force microscopy. Polymer 1998, 39, 2437-2446. [CrossRef]

26. Beekmans, L.G.M.; Hempenius, M.A.; Vancso, G.J. Morphological development of melt crystallized poly(propylene oxide) by in situ AFM: Formation of banded spherulites. Eur. Polym. J. 2004, 40, 893-903. [CrossRef] 
27. Xu, J.; Guo, B.H.; Zhang, Z.M.; Zhou, J.J.; Jiang, Y.; Yan, S.; Li, L.; Wu, Q.; Chen, G.Q.; Schultz, J.M. Direct AFM observation of crystal twisting and organization in banded spherulites of chiral poly(3-hydroxybutyrate-co-3-hydroxyhexanoate). Macromolecules 2004, 37, 4118-4123. [CrossRef]

28. Fujiwara, Y. The superstructure of melt-crystallized polyethylene. I. Screwlike orientation of unit cell in polyethylene spherulites with periodic extinction rings. J. Appl. Polym. Sci. 1960, 4, 10-15. [CrossRef]

29. Gazzano, M.; Focarete, M.L.; Riekel, C.; Scandola, M. Structural study of poly(L-lactic acid) spherulites. Biomacromolecules 2004, 5, 553-558. [CrossRef] [PubMed]

30. Gazzano, M.; Focarete, M.L.; Riekel, C.; Ripamonti, A.; Scandola, M. Structural investigation of poly(3-hydroxybutyrate) spherulites by microfocus X-ray diffraction. Macromol. Chem. Phys. 2001, 202, 1405-1409. [CrossRef]

31. Nozue, Y.; Hirano, S.; Kurita, R.; Kawasaki, N.; Ueno, S.; Iida, A.; Nishi, T.; Amemiya, Y. Co-existing handednesses of lamella twisting in one spherulite observed with scanning microbeam wide-angle X-ray scattering. Polymer 2004, 45, 8299-8302. [CrossRef]

32. Hsieh, Y.T.; Ishige, R.; Higaki, Y.; Woo, E.M.; Takahara, A. Microscopy and microbeam X-ray analyses in poly(3-hydroxybutyrate-co-3-hydroxyvalerate) with amorphous poly(vinyl acetate). Polymer 2014, 55, 6906-6914. [CrossRef]

33. Rosenthal, M.; Portale, G.; Burghammer, M.; Bar, G.; Samulski, E.T.; Ivanov, D.A. Exploring the origin of crystalline lamella twist in semi-rigid chain polymers: The model of Keith and Padden revisited. Macromolecules 2012, 45, 7454-7460. [CrossRef]

34. Rosenthal, M.; Burghammer, M.; Bar, G.; Samulski, E.T.; Ivanov, D.A. Switching chirality of hybrid left-right crystalline helicoids built of achiral polymer chains: When right to left becomes left to right. Macromolecules 2014, 47, 8295-8304. [CrossRef]

35. Hikima, Y.; Morikawa, J.; Hashimoto, T. Wavenumber dependence of FT-IR image of molecular orientation in banded spherulites of poly(3-hydroxybutyrate) and poly(l-lactic acid). Macromolecules 2013, 46, 1582-1590. [CrossRef]

36. Jin, Y.; Wang, W.; Su, Z. Infrared imaging of ring-banded spherulites formed in poly(L-lactide)-poly(ethylene glycol) diblock copolymer: Segment distribution and orientation. Appl. Spectrosc. 2011, 65, 454-458. [CrossRef] [PubMed]

37. Ellis, G.J.; Martin, M.C. Opportunities and challenges for polymer science using synchrotron-based infrared spectroscopy. Eur. Polym. J. 2016, 81, 505-531. [CrossRef]

38. Sun, X.; Gao, N.; Li, Q.; Zhang, J.; Yang, X.; Ren, Z.; Yan, S. Crystal morphology of poly(3-hydroxybutyrate) on amorphous poly(vinylphenol) substrate. Langmuir 2016, 32, 3983-3994. [CrossRef] [PubMed]

39. Enrique-Jimenez, P.; Vega, J.F.; Martínez-Salazar, J.; Ania, F.; Flores, A. Mapping the mechanical properties of poly(3-hydroxybutyrate-co-3-hydroxyvalerate) banded spherulites by nanoindentation. Polymers 2016, 8, 358. [CrossRef]

40. Jiang, Y.; Zhou, J.J.; Li, L.; Xu, J.; Guo, B.H.; Zhang, Z.M.; Wu, Q.; Chen, G.Q.; Weng, L.T.; Cheung, Z.L.; et al. Surface properties of poly(3-hydroxybutyrate-co-3-hydroxyvalerate) banded spherulites studied by atomic force microscopy and time-of-flight secondary ion mass spectrometry. Langmuir 2003, 19, 7417-7422. [CrossRef]

41. Wang, Z.; Li, Y.; Yang, J.; Gou, Q.; Wu, Y.; Wu, X.; Liu, P.; Gu, Q. Twisting of lamellar crystals in poly(3-hydroxybutyrate-co-3-hydroxyvalerate) ring-banded spherulites. Macromolecules 2010, 43, 4441-4444. [CrossRef]

42. Xu, J.; Guo, B.H.; Zhou, J.J.; Li, L.; Wu, J.; Kowalczuk, M. Observation of banded spherulites in pure poly(L-lactide) and its miscible blends with amorphous polymers. Polymer 2005, 46, 9176-9185. [CrossRef]

43. Oaki, Y.; Imai, H. Amplification of chirality from molecules into morphology of crystals through molecular recognition. J. Am. Chem. Soc. 2004, 126, 9271-9275. [CrossRef] [PubMed]

44. Shtukenberg, A.G.; Gujral, A.; Rosseeva, E.; Cui, X.; Kahr, B. Mechanics of twisted hippuric acid crystals untwisting as they grow. CrystEngComm 2015, 17, 8817-8824. [CrossRef]

45. Cui, X.; Rohl, A.L.; Shtukenberg, A.; Kahr, B. Twisted aspirin crystals. J. Am. Chem. Soc. 2013, 135, 3395-3398. [CrossRef] [PubMed]

46. Frömsdorf, A.; Woo, E.M.; Lee, L.T.; Chen, Y.F.; Förster, S. Atomic force microscopy characterization and interpretation of thin-film poly(butylene adipate) spherulites with ring bands. Macromol. Rapid Commun. 2008, 29, 1322-1328. [CrossRef] 
47. Woo, E.M.; Lugito, G. Origins of periodic bands in polymer spherulites. Eur. Polym. J. 2015, 71, 27-60. [CrossRef]

48. Lugito, G.; Woo, E.M.; Chuang, W.T. Interior lamellar assembly and optical birefringence in poly(trimethylene terephthalate) spherulites: Mechanisms from past to present. Crystals 2017, 7, 56. [CrossRef]

49. Xu, J.; Guo, B.H.; Wu, Q.; Chen, J.C.; Chen, G.Q.; Zhou, J.J.; Jiang, Y.; Li, L. Organization process of the hierarchical structures in microbially synthesized polyhydroxyalkanoates. Curr. Appl. Phys. 2007, 7 (Suppl. 1), e41-e44. [CrossRef]

50. Toda, A.; Arita, T.; Hikosaka, M. Three-dimensional morphology of PVDF single crystals forming banded spherulites. Polymer 2001, 42, 2223-2233. [CrossRef]

51. Toda, A.; Okamuraa, M.; Hikosakaa, M.; Nakagawa, Y. AFM observation of polyethylene single crystals: Selective handedness of screw dislocations in a chair type. Polymer 2003, 44, 6135-6138. [CrossRef]

52. Toda, A.; Okamura, M.; Taguchi, K.; Hikosaka, M.; Kajioka, H. Branching and higher order structure in banded polyethylene spherulites. Macromolecules 2008, 41, 2484-2493. [CrossRef]

53. Barham, P.J.; Keller, A.; Otun, E.L.; Holmes, P.A. Crystallization and morphology of a bacterial thermoplastic: Poly-3-hydroxybutyrate. J. Mater. Sci. 1984, 19, 2781-2794. [CrossRef]

54. Singfield, K.L.; Hobbs, J.K.; Keller, A. Correlation between main chain chirality and crystal "twist" direction in polymer spherulites. J. Cryst. Growth 1998, 183, 683-689. [CrossRef]

55. Point, J.J. Structure fibreuse et phénomènes de cristallisation rayonnante dans les hauts polymères sphérolithiques. Bull. Acad. R. Belg. 1955, 41, 974-981.

56. Lovinger, A.J.; Chua, J.O.; Gryte, C.C. Studies on the $\alpha$ and $\beta$ forms of isotactic polypropylene by crystallization in a temperature gradient. J. Polym. Sci. Polym. Phys. Ed. 1977, 15, 641-656. [CrossRef]

57. Kawashima, K.; Kawano, R.; Miyagi, T.; Umemoto, S.; Okui, N. Morphological changes in flat-on and edge-on lamellae of poly(ethylene succinate) crystallized from molten thin films. J. Macromol. Sci. Part B Phys. 2003, B42, 889-899. [CrossRef]

58. Ding, M.; Yu, J.; He, J.; Zhang, J. An unusual spherulite morphology induced by nano-fillers from a concentrated cellulose/ionic liquid solution. RSC Adv. 2015, 5, 44648-44651. [CrossRef]

59. Singfield, K.L.; Klass, J.M.; Brown, G.R. Optically active polyethers. 2. Atomic force microscopy of melt-crystallized poly(epichlorohydrin) enantiomers and their equimolar blend. Macromolecules 1995, 28, 8006-8015. [CrossRef]

60. Rosenthal, M.; Hernandez, J.J.; Odarchenko, Y.I.; Soccio, M.; Lotti, N.; Di Cola, E.; Burghammer, M.; Ivanov, D.A. Non-radial growth of helical homopolymer crystals: Breaking the paradigm of the polymer spherulite microstructure. Macromol. Rapid Commun. 2013, 34, 1815-1819. [CrossRef] [PubMed]

61. Hoffman, J.D.; Lauritzen, J.I., Jr. Crystallization of bulk polymers with chain folding: Theory of growth of lamellar spherulites. J. Res. Nat. Bur. Stand. 1961, 65A, 297. [CrossRef]

62. Schultz, J.M.; Kinloch, D.R. Transverse screw dislocations: A source of twist in crystalline polymer ribbons. Polymer 1969, 10, 271-278. [CrossRef]

63. Bassett, D.C.; Hodge, A.M. On the morphology of melt-crystallized polyethylene. III. Spherulitic organization. Proc. R. Soc. Lond. Ser. A 1981, 377, 61-71. [CrossRef]

64. Schultz, J.M. Self-induced field model for crystal twisting in spherulites. Polymer 2003, 44, 433-441. [CrossRef]

65. Keller, A.; Sawada, S. On the interior morphology of bulk polyethylene. Makromol. Chem. 1964, 74, $190-221$. [CrossRef]

66. Lotz, B.; Gonthier-Vassal, A.; Brack, A.; Magoshi, J. Twisted single crystals of Bombyx mori silk fibroin and related model polypeptides with $\beta$ structure: A correlation with the twist of the $\beta$ sheets in globular proteins. J. Mol. Biol. 1982, 156, 345-357. [CrossRef]

67. Punin, Y.O. Growth of Crystals; Consultants Bureau: New York, NY, USA, 1983; Volume 14, pp. 121-131.

68. Punin, Y.O. Structural and orientational instability of crystals during their growth. J. Struct. Chem. 1994, 35, 616-624. [CrossRef]

69. Shtukenberg, A.G.; Freudenthal, J.; Kahr, B. Reversible twisting during helical hippuric acid crystal growth. J. Am. Chem. Soc. 2010, 132, 9341-9349. [CrossRef] [PubMed]

70. Shtukenberg, A.G.; Punin, Y.O.; Gunn, E.; Kahr, B. Spherulites. Chem. Rev. 2012, 112, 1805-1838. [CrossRef] [PubMed]

71. Wang, J.S.; Ye, H.M.; Qin, Q.H.; Xu, J.; Feng, X.Q. Anisotropic surface effects on the formation of chiral morphologies of nanomaterials. Proc. R. Soc. A 2012, 468, 609-633. [CrossRef] 
72. Liu, J.; Ye, H.M.; Xu, J.; Guo, B.H. Formation of ring-banded spherulites of $\alpha$ and $\beta$ modifications in poly(butylene adipate). Polymer 2011, 52, 4619-4630. [CrossRef]

73. Ivanov, D.A.; Rosenthal, M. Microstructure of banded polymer spherulites: New insights from synchrotron nanofocus X-ray scattering. Adv. Polym. Sci. 2017, 277, 95-126.

74. Huang, Y.; Luo, X.; Ma, D. Ringed spherulite morphology and compatibility in the binary blends of poly(E-caprolactone) with ethyl cellulose. Eur. Polym. J. 2001, 37, 2153-2157.

75. Schulze, K.; Kressler, J.; Kammer, H.W. Phase behaviour of poly( $\varepsilon$-caprolactone)/(polystyrene-ran-acrylonitrile) blends exhibiting both liquid-liquid unmixing and crystallization. Polymer 1993, 34, 3704-3709. [CrossRef]

76. Keith, H.D.; Padden, F.J.; Russell, T.P. Morphological changes in polyesters and polyamides induced by blending with small concentrations of polymer diluents. Macromolecules 1989, 22, 666-675. [CrossRef]

77. Ma, D.; Luo, X.; Zhang, R.; Nishi, T. Miscibility and spherulites in blends of poly(E-caprolactone) with ethylene terephthalate-caprolactone copolyester. Polymer 1996, 37, 1575-1581.

78. Wang, Z.; Wang, X.; Yu, D.; Jiang, B. The formation of ring-banded spherulites of poly( $\varepsilon$-caprolactone) in its miscible mixtures with poly(styrene-co-acrylonitrile). Polymer 1997, 38, 5897-5901. [CrossRef]

79. Wen, T.; Shen, H.Y.; Wang, H.F.; Mao, Y.C.; Chuang, W.T.; Tsai, J.C.; Ho, R.M. Controlled handedness of twisted lamellae in banded spherulites of isotactic poly(2-vinylpyridine) as induced by chiral dopants. Angew. Chem. Int. Ed. 2015, 54, 14313-14316. [CrossRef] [PubMed]

80. Cui, X.; Shtukenberg, A.G.; Freudenthal, J.; Nichols, S.; Kahr, B. Circular birefringence of banded spherulites. J. Am. Chem. Soc. 2014, 136, 5481-5490. [CrossRef] [PubMed]

81. Li, M.C.; Wang, H.F.; Chiang, C.H.; Lee, Y.D.; Ho, R.M. Lamellar-twisting-induced circular dichroism of chromophore moieties in banded spherulites with evolution of homochirality. Angew. Chem. Int. Ed. 2014, 53, 4450-4455. [CrossRef] [PubMed]

82. Xu, J.; Bao, J.; Guo, B.H.; Ma, H.; Yun, T.L.; Gao, L.; Chen, G.Q.; Iwata, T. Imaging of nonlinear optical response in biopolyesters via second harmonic generation microscopy and its dependence on the crystalline structures. Polymer 2007, 48, 348-355. [CrossRef]

(C) 2017 by the authors. Licensee MDPI, Basel, Switzerland. This article is an open access article distributed under the terms and conditions of the Creative Commons Attribution (CC BY) license (http:/ / creativecommons.org/licenses/by/4.0/). 